\title{
MicroRNA-155 affects oxidative damage through regulating autophagy in endothelial cells
}

\author{
HUIFEN CHEN $^{1 *}$, MI YANG LIU GAO ${ }^{2 *}$, LI ZHANG $^{3}$, FA LIAN HE ${ }^{2}$, \\ YAN KUN SHI ${ }^{3}$, XING HUA PAN ${ }^{2}$ and $\mathrm{HONG} \mathrm{WANG}^{3}$ \\ ${ }^{1}$ Department of Cardiology, Hengyang Central Hospital, Hengyang, Hunan 421000; \\ Departments of ${ }^{2}$ Clinical Experiment and ${ }^{3}$ Geriatrics, Kunming General Hospital, Kunming, Yunnan 650032, P.R. China
}

Received August 30, 2017; Accepted September 3, 2018

DOI: $10.3892 / \mathrm{ol} .2018 .9860$

\begin{abstract}
MicroRNA-155 (miRNA-155) is a typical multifunctional miRNA, which serves a crucial role in the regulation of numerous vessel cells. However, its effects on dysfunctional endothelial cells have not been completely elucidated. In order to investigate the signaling pathway of miRNA-155-induced cell injury, $\mathrm{H}_{2} \mathrm{O}_{2}$ was used to establish an oxidative stress cell model, and miR-155 was transfected into $\mathrm{H}_{2} \mathrm{O}_{2}$-treated cells. The CCK8 assay was then employed to examine the effect of miR-155 on the cell proliferations of $\mathrm{H}_{2} \mathrm{O}_{2}$-treated cells, and the expressions of Microtubule Associated Protein 1 Light Chain 3 (LC3) and Sequestosome 1 (P62) were detected to examine the effect of miR-155 on the autophagy of Human umbilical vein endothelial cells, and then the formation of intracellular autophagosomes was observed. The results indicated that endothelial cell proliferation was promoted, and oxidant-induced injury was decreased when the expression of miR-155 was inhibited. In addition, the results also demonstrated that when the miR-155 inhibitor was used, the expression of LC3 was increased and the expression of P62 was decreased. This suggests that modulated miR-155 can prevent oxidative damage in endothelial cells, by regulating the level of autophagy. Furthermore, the present study also demonstrated that miR-155 regulated autophagy via promotion of the expression of the autophagy-related gene, Autophagy Related 5 (ATG5). In conclusion, the attenuated expression of
\end{abstract}

Correspondence to: Dr Hong Wang, Department of Geriatrics, Kunming General Hospital, 212 Da Guan Road, Xishan, Kunming, Yunnan 650032, P.R. China

E-mail:wangh43@126.com

Dr Xing Hua Pan, Department of Clinical Experiment, Kunming General Hospital, 212 Da Guan Road, Xishan, Kunming, Yunnan 650032, P.R. China

E-mail: xinghuapan@aliyun.com

*Contributed equally

Key words: miR-155, endothelial cells, autophagy, reactive oxygen species
miR-155 can decrease oxidant-induced injury and promote cell proliferation via upregulating autophagy, which subsequently affects the expression of ATG5. The present study provides a novel insight into microRNAs as potential therapeutics for the treatment of heart disease.

\section{Introduction}

Vascular endothelial cells participate in numerous physiological processes, such as endocrine modulation and inflammatory reactions (1). Atherosclerosis, which can lead to heart failure, is a primary vascular disease caused by endothelial dysfunction (2). Previous findings have demonstrated that atherosclerosis has a high morbidity and mortality (3). During the process of atherosclerosis, platelet aggregation occurs, and lipids invade vascular cells leading to hypoxia; thereby inducing endothelial cell dysfunction, and atypical electron leaking from the mitochondria will produce the reactive oxygen species (ROS) $(4,5)$, which can result in endothelial cell dysfunction.

MicroRNAs (miRNAs) not only block messenger RNA (mRNA) duplication and translation, they can also affect cell proliferation, differentiation, apoptosis and autophagy by regulating the expression of target genes (6). miR-155 is a multifunctional miRNA, which is transcribed from chromosome 21 of the B-cell Integration Cluster (7). Previous research demonstrated that miR-155 is abnormally expressed in several types of human cancer, including endometrial cancer and lymphoma (8), with studies indicating that miR-155 has a potential therapeutic effect on vascular disease by enhancing the viability of vascular cells $(6,9)$.

Autophagy is an evolutionarily conserved stress response in eukaryotes (10), and can improve cell viability under conditions of cellular stress. An autophagosome is a vacuole structure with a double-membrane that is located in the cytoplasm, which can digest dysfunctional proteins and organelles $(11,12)$. Autophagy-related genes can regulate autophagosome formation to impact the process of autophagy (13). However, the effects and mechanism of miR-155 in endothelial cells through autophagy under the conditions of oxidative stress have not been completely elucidated.

In the present study, miR-155 was transfected into $\mathrm{H}_{2} \mathrm{O}_{2}$-treated endothelial cells. The CCK8 assay was used 
to examine the effect of miR-155 on the proliferation of $\mathrm{H}_{2} \mathrm{O}_{2}$-treated cells, and the expressions of Microtubule Associated Protein 1 Light Chain $3 \alpha$ (LC3) and (Nucleoporin 62) P62 were detected to examine the effect of miR-155 on the autophagy of Human umbilical vein endothelial cells (HUVECs), and the tandem-fluorescent-adenovirus was used to observe the intracellular autophagosome formation. The results demonstrated that the proliferation of endothelial cells under oxidative stress was promoted and the expression of LC3 and P62 was increased and decreased respectively. The results also demonstrated that miR-155 modulated autophagy via promoting autophagy-related genes (ATG5) expression.

\section{Materials and methods}

Cell culture. Human umbilical vein endothelial cells (HUVECs) were obtained from iCell Bioscience, Inc. (Shanghai, China), The cells were cultured in a $7.5 \mathrm{~cm}^{2}$ culture flask (Corning Incorporated, Corning, NY, USA) in (450 mg/l) high-glucose DMEM (Gibco; Thermo Fisher Scientific, Inc., Waltham, MA, USA) supplemented with $10 \%$ fetal bovine serum (FBS; Hyclone; GE Healthcare Life Sciences, Logan, UT, USA), $1 \%$ endothelial growth factor and $1 \%$ penicillin and streptomycin (Hyclone; GE Healthcare Life Sciences). All the cells were cultured in an incubator at $37^{\circ} \mathrm{C}$ with $5 \% \mathrm{CO}_{2}$. The experiments were conducted in triplicate at least 3 times.

Treatment of the HUVECs by use of $\mathrm{H}_{2} \mathrm{O}_{2}$. Hydrogen peroxide $\left(\mathrm{H}_{2} \mathrm{O}_{2}\right.$, Sinopharm Chemical Reagent Co., Ltd., Shanghai, China) at $30 \%$ was used to treat the HUVECs at concentrations of $0,100,200,400$ and $800 \mathrm{nmol} / 1$ for $24 \mathrm{~h}$ at $37^{\circ} \mathrm{C}$ prior to experimentation. The suit concentration of $\mathrm{H}_{2} \mathrm{O}_{2}$, which produced cytotoxic ROS was selected to treat the HUVECs in order to establish the oxidative stress cell model. A final concentration of $5 \mu \mathrm{M}$ 3-methyladenine (3-MA; Beyotime Institute of Biotechnology, Haimen, China) was used to treat the cells of the contrast group at $37^{\circ} \mathrm{C}$. The experiments were conducted in triplicate at least 3 times.

Transfection of small interfering RNA (siRNA). The sequence of miR-155-5p mimics was 5'-UUAAUGCUAAUCGUCAUA GGGGU-3', the sequence of miR-155-5p inhibitor was 5'-ACC CCUAUCACGAUUAGCAUUAA-3' and the siRNA sequence of miR-155 was 5'-GACAAUUACGAUUAGCACUAUCCC CAAAAACGGAGGUUGACUGAGGAUGUAUAAUCGUAA UUGUC-3', miR-155-5p mimics, miR-155-5p inhibitor and siRNA of miR-155 was purchased from Generay Biotech Co., Ltd. (Shanghai, China), The concentration of siRNA was $5 \mathrm{uM}$. The HUVECs were cultured in a $6 \mathrm{~cm}^{2}$ petri dish (Corning Life Sciences, Wujiang, China) at a density of $5 \times 10^{5} \mathrm{cell} / \mathrm{cm}^{2}$, the cells were transfected with $100 \mu \mathrm{mol} / 1$ siRNA miR-155 as the miR-155 negative control, miR-155 inhibitor and miR-155 mimic groups, by using a ribo FECT $^{\mathrm{TM}} \mathrm{CP}$ Transfection kit (Guangzhou RiboBio Co., Ltd., Guangzhou, China) according to the manufacturer's protocol, and the cells were subsequently incubated in fresh High Glucose-DMEM (Gibco; Thermo Fisher Scientific, Inc.) for $24 \mathrm{~h}$ at $37^{\circ} \mathrm{C}$ prior to treatment with $\mathrm{H}_{2} \mathrm{O}_{2}$. The experiments were conducted in triplicate at least 3 times.
Transfection of fluorescent-mRFP-GFP-LC3 adenovirus. To detect intracellular autophagy, the fluorescent-mRFP-GFP-LC3 adenovirus (Hanbio Biotechnology Co., Ltd., Shanghai, China) was transfected into the HUVECs, miR-155 was transfected into four groups of cells, comprising miR-155 inhibitor negative control, miR-155 inhibitor, miR-155 mimic negative control and miR-155 mimic groups, prior to treatment with $\mathrm{H}_{2} \mathrm{O}_{2}$, then $50 \mu \mathrm{l}$ adenovirus and $8 \mu \mathrm{l}$ polybrane were added. Following co-culture for $48 \mathrm{~h}$ at $37^{\circ} \mathrm{C}$, the number of fluorescent puncta in cells were counted using immunofluorescence laser confocal laser scanning microscopy (magnification, $x 40$ ). Green fluorescent protein (GFP), displayed as green dots, represent the acidic lysosome. The red fluorescent proteins (RFP) represent the autophagy lysosome. When the number of green spots increased, the level of autophagy was reduced. mRFP merged with GFP, displayed as yellow dots, and represented the autophagosome. The experiments were repeated 3 times.

Reverse transcription-quantitative polymerase chain reaction (RT-qPCR). The total RNA of each group (miR-155 inhibitor negative control, miR-155 inhibitor, miR-155 mimic negative control and miR-155 mimic groups) was extracted from cultured cells using TRIzol reagent (Thermo Fisher Scientific, Inc.). The reverse transcription was performed by use of PrimeScript ${ }^{\mathrm{TM}}$ RT reagent kit (Takara Biotechnology Co., Ltd., Dalian, China) to synthesize complementary DNA (cDNA), according to the manufacturer's protocol. The cDNA reverse transcription procedure was as follows: $42^{\circ} \mathrm{C}$ for $15 \mathrm{~min}$ followed with $85^{\circ} \mathrm{C}$ for $2 \mathrm{~min}$. The primer sequences used are listed in Table I. The qPCR Master Mix (Promega Corporation, Madison, WI, USA) was used according to the manufacturer's protocol, RT-qPCR was performed using a LightCycler 480 Real-Time system. The thermocycling conditions were as follows: $95^{\circ} \mathrm{C}$ for $5 \mathrm{~min}$, and then 40 cycles of $95^{\circ} \mathrm{C}$ for $15 \mathrm{sec}$ and $60^{\circ} \mathrm{C}$ for $1 \mathrm{~min}$, and finally 1 cycle of $95^{\circ} \mathrm{C}$ for $15 \mathrm{sec}, 60^{\circ} \mathrm{C}$ for $1 \mathrm{~min}$ and $95^{\circ} \mathrm{C}$ for $15 \mathrm{sec}$. GAPDH was a housekeeping gene for normalized the relative target mRNA expression, and the comparative $2^{-\Delta \Delta \mathrm{Cq}}$ method was used to quantify target gene expression (14). The experiments were repeated 3 times.

Western blot analysis. To extract proteins from HUVECs, the cells were washed twice with phosphate-buffered saline (PBS) in $25^{\circ} \mathrm{C}$ for $5 \mathrm{~min}$ and then lysed in ice-cold RIPA buffer containing 0.5 nMPMSF(BeyotimeInstitute of Biotechnology). The lysates were centrifuged at $15,000 \mathrm{x} \mathrm{g}$ in $4^{\circ} \mathrm{C}$ for $15 \mathrm{~min}$. The BCA protein assay kit (Thermo scientific, Inc.) was then used to detect the protein concentrations, and $20 \mu \mathrm{g}$ protein were separated by $12 \%$ SDS-PAGE gels, then transferred to polyvinylidene difluoride membranes, following blocking in $5 \%$ non-fat milk of TBS with $0.05 \%$ Tween- 20 at $4^{\circ} \mathrm{C}$ for $2 \mathrm{~h}$. The membranes were then incubated with primary antibodies [LC3 A/B rabbit anti-mouse polyclonal antibody (1:1,000; cat. no. ab128025), ATG5 rabbit anti-mouse monoclonal antibody (1:1,000; cat. no. ab108327) and GAPDH mouse anti-rabbit monoclonal antibody $(1: 2,000$; cat. no. ab8245; all Abcam Cambridge, MA, USA)] and P62 rabbit anti-mouse monoclonal antibody (1:1,000; cat. no. 8025; Cell Signaling Technology, Inc.) at $4^{\circ} \mathrm{C}$ overnight, followed by incubation with secondary 
Table I. Primer sequences used in the present study.

\begin{tabular}{cc}
\hline Target gene & \multicolumn{2}{c}{ Primer sequence } \\
\hline miR-155 & \\
Forward & 5'-GCTTCGGTTAATGCTAATCGTG-3' \\
Reverse & 5'-CAGAGCAGGGTCCGAGGTA-3' \\
LC3A & \\
Forward & 5'-GGCTTCCGAGTTGCTGACTG-3' \\
Reverse & 5'-CTGGTCGCGGATCTGCTGTA-3' \\
LC3B & \\
Forward & 5'-AGTTGGCACAAACGCAGGGTA-3' \\
Reverse & 5'-TTAGGAGTCAGGGACCTTCAGCA-3' \\
P62 & \\
Forward & 5'-AGTCTCTGGCGGAGCAGATGA-3' \\
Reverse & 5'-TCTGGCATCTGTAGGGACTGGA-3' \\
ATG5 & \\
Forward & 5'-CCATCAATCGGAAACTCATGGA-3' \\
Reverse & 5'-ATCTGCAGCCACAGGACGAA-3' \\
GAPDH & \\
Forward & 5'-GAAGGGCTCATGACCACAGTCCAT-3' \\
Reverse & 5'-TCATTGTCGTACCAGGAAATGAGCTT-3'
\end{tabular}

miR-155, microRNA-155; LC3A, Microtubule Associated Protein 1 Light Chain 3; LC3; P62, Sequestosome 1; ATG5, Autophagy Related 5.

antibodies [goat polyclonal anti-rabbit $\operatorname{IgG}(1: 5,000$; cat. no. ab6721) and goat polyclonal anti-mouse $\operatorname{IgG}(1: 2,000$; cat. no. ab6789; both Abcam)] for $2 \mathrm{~h}$ at $37^{\circ} \mathrm{C}$. The results were observed by using an enhanced chemiluminescence detection system (Thermo Fisher Scientific, Inc.). The experiments were repeated 3 times.

Detecting intracellular ROS by use of superoxide dismutase (SOD) assay kit. The supernatant of adherence cultured cells was removed and cells were washed with PBS twice in $25^{\circ} \mathrm{C}$ for $5 \mathrm{~min}$, then RIPA buffer (Beyotime Institute of Biotechnology) was used to split cells, and following centrifugation at $12,000 \mathrm{xg}$ for $10 \mathrm{~min}$ in $4^{\circ} \mathrm{C}$, the supernatant was collected. The dye conversion of 4-[3-(4-iodophenyl)-2-(4 -nitrophenyl)-2H5-tetrazolium]-1,3-benzene disulfonate to formazan (WST-1 Cell Proliferation and Cytotoxicity Assay kit; Beyotime institute of Biotechnology) was used to detect the intracellular ROS. Cells were plated at 7,500 cells/well into 96 well tissue culture plates and then were allowed to attach at $37^{\circ} \mathrm{C}$ for $12 \mathrm{~h}$. Subsequently, the cells were treated by $5 \mu \mathrm{M} / 1$ 3-MA at $37^{\circ} \mathrm{C}$ until autophagy occurs, and then the media was replaced with ischemic buffer at $37^{\circ} \mathrm{C}$ for $30 \mathrm{~min}$ followed by being replaced with High-Glucose DMEM supplemented with $10 \% \mathrm{FBS}, 1 \%$ endothelial growth factor and $1 \%$ penicillin and streptomycin in the absence or presence of BHA $(0.1 \mathrm{mM}$; cat. no. 1009005) and NAC (5 mM; cat. no. 20021; both from Sigma-Aldrich; Merck KGaA, Darmstadt, Germany) for $24 \mathrm{~h}$ at $37^{\circ} \mathrm{C}$, WST-1 reagent was added in 24-h increments up to $72 \mathrm{~h}$ at $37^{\circ} \mathrm{C}$, following the manufacturer's protocols, and absorbance was recorded using a microplate reader (Thermo Fisher Scientific, Inc.) at $450 \mathrm{~nm}$ wavelength. The experiments were conducted in triplicate at least 3 times (15).

Cell counting kit- 8 assay. The CCK- 8 assay kit (Beyotime Institute of Biotechnology) was used to detect the impact of miR-155 on cell proliferation. HUVECs were plated in 96-well plates at a density of $2 \times 10^{4}$ cell/well and were cultured for $24 \mathrm{~h}$ at $37^{\circ} \mathrm{C}$. Subsequently, $10 \mu \mathrm{l} \mathrm{CCK}-8$ reagent with $100 \mu$ l culture medium was added to each well for $2 \mathrm{~h}$ at $37^{\circ} \mathrm{C}$. The cells were measured at a wavelength of $450 \mathrm{~nm}$ using a microplate reader according to the manufacturer's protocol. The experiments were repeated 3 times.

Statistical analysis. SPSS 16.0 (SPSS, Inc., Chicago, IL, USA) was used to perform statistical analysis. A Student's paired t-test was used to compare between two groups by use of an open source software $\mathrm{R}$ language 3.5.0 (https://www.7down.com/soft/288188.html), and one-way analysis of variance (ANOVA) with Bonferroni post hoc correction was performed to compare the results between $\leq 3$ groups, The one-way ANOVA results were conducted by $\mathrm{R}$ software written by computer programmers from Department of Geriatrics in Kunming General Hospital (Kunming, China). The data are a result of at least three independent experimental repeats, and are presented as mean \pm standard deviation (SD). $\mathrm{P}<0.05$ was considered to indicate a statistically significant difference.

\section{Results}

Establishment of oxidative stress endothelial HUVECs model. A previous study reported that $\mathrm{H}_{2} \mathrm{O}_{2}$-treated cells released ROS, which can cause damage in cells, and LC3 I will convert into LC3 II when conjugated with phosphatidylethanolamine (16). The ratio of LC3 II/I was used to identify the activation of autophagy (17). In the present study, $\mathrm{H}_{2} \mathrm{O}_{2}$ at concentrations of $0,100,200,400$, and $800 \mathrm{nmol} / 1$ were used to treat the cultured HUVECs for $24 \mathrm{~h}$, and the expression of LC3 was detected to study the change of autophagy. The expression of P62 was also detected as a marker for autophagy. Furthermore, tandem-fluorescent-adenovirus was used to observe the intracellular autophagosome information. The SOD assay was then performed to examine ROS damage in endothelial cells.

The expression of LC3 I/II was its highest in HUVECs with an $\mathrm{H}_{2} \mathrm{O}_{2}$ concentration of $400 \mathrm{nmol} / \mathrm{l}$, and the expression of LC3 I/II was decreased in HUVECs when $\mathrm{H}_{2} \mathrm{O}_{2}$ was administered at $800 \mathrm{nmol} / \mathrm{l}$, as cell damage could not be repaired, thus leading to cell apoptosis (Fig. 1A). The results (Fig. 1B) confirmed the findings of Fig. 1A. Consequently, $400 \mathrm{nmol} / 1$ of $\mathrm{H}_{2} \mathrm{O}_{2}$ was used in subsequent experimentations to induce autophagy in HUVECs.

Downregulation of miR-155 can promote HUVEC proliferation. $\mathrm{miR}-155$, the mimic $\mathrm{miR}-155$ and the negative control miR-155 were transfected into $\mathrm{H}_{2} \mathrm{O}_{2}$-treated HUVECs. The CCK- 8 assay was performed to detect HUVEC proliferation; the results demonstrated that cell proliferation in the miR-155 inhibitor group was higher compared with 

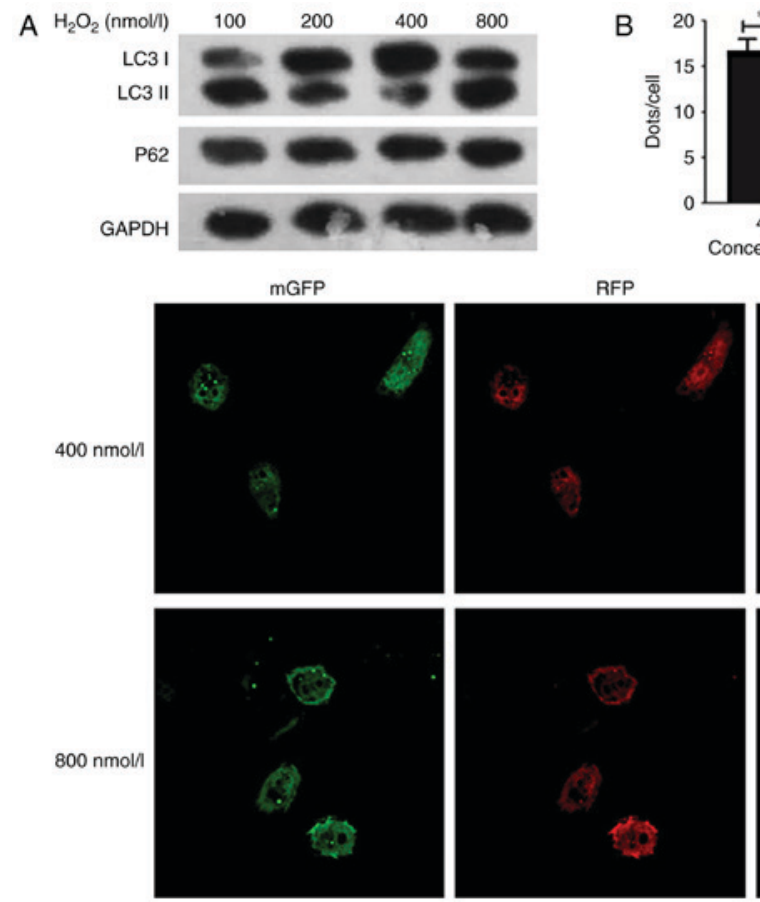

Gellow dots
口Red dots

Figure $1 . \mathrm{H}_{2} \mathrm{O}_{2}$ at $400 \mathrm{nmol} / \mathrm{l}$ can be used to induce autophagy in HUVECs. (A) Western blotting demonstrates that the expression of LC3 I/II was increased and the expression of $\mathrm{P} 62$ was decreased markedly, at $400 \mathrm{nmol} / 1 \mathrm{H}_{2} \mathrm{O}_{2}$. The RFP-mGFP-LC3-adenovirus was transfected into endothelial cells; immunofluorescence laser scanning confocal microscopy was used to count the yellow dots of cells. (B) The number of yellow dots were significantly increased compared with red dots, at $\mathrm{H}_{2} \mathrm{O}_{2}$ concentrations of 400 and $800 \mathrm{nmol} / 1 .{ }^{* *} \mathrm{P}<0.01, \mathrm{n}=3$ (magnification, x100). HUVECs, Human umbilical vein endothelial cells; LC3, Microtubule Associated Protein 1 Light Chain $3 \alpha$; P62, Nucleoporin 62.
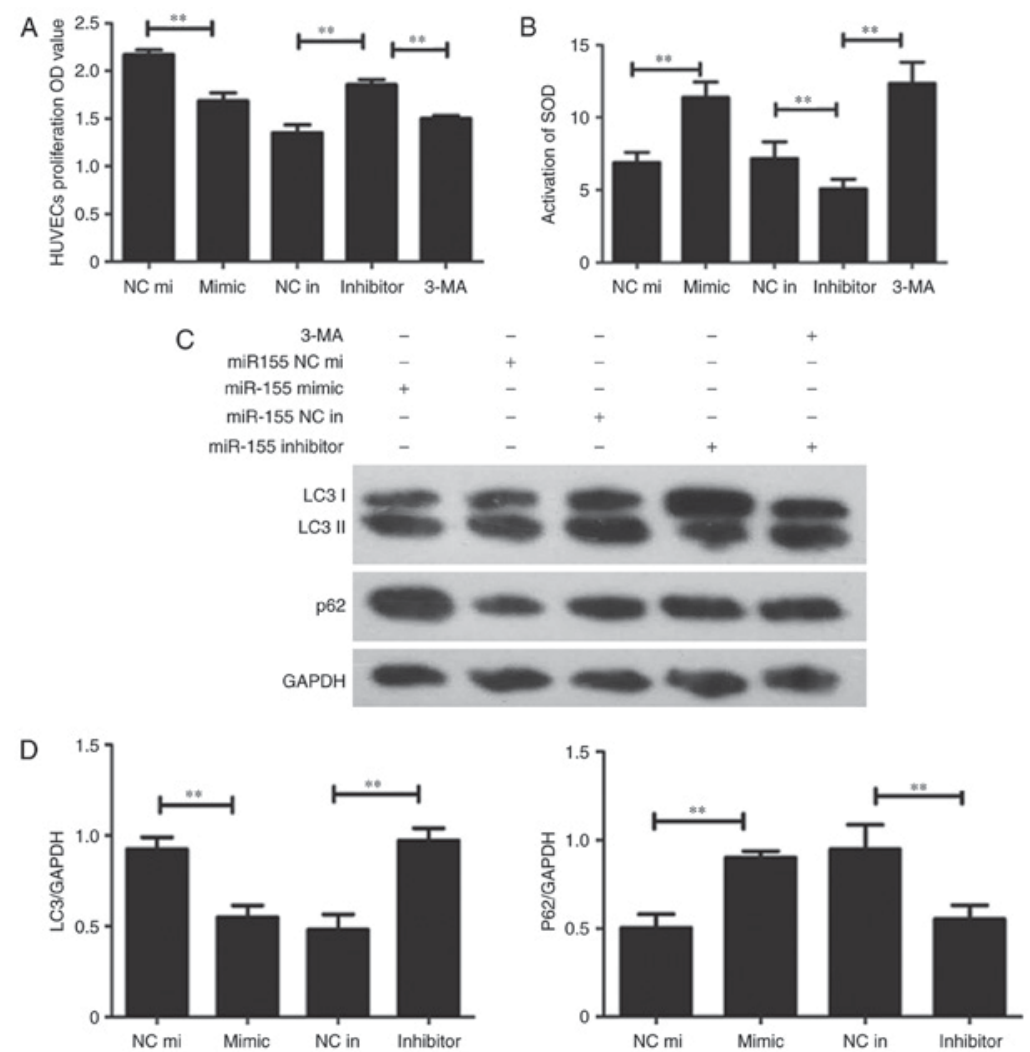

Figure 2. Downregulation of miR-155 promotes HUVEC proliferation. (A) Statistical data of the CCK-8 assay. The OD value at $450 \mathrm{~nm}$ was increased in the group transfected with the miR-155 inhibitor $\left({ }^{* *} \mathrm{P}<0.01, \mathrm{n}=3\right)$. (B) The Superoxide Dismutase assay was used to detect the activation of intracellular ROS following transfection with miR-155, the activation of ROS was decreased in the miR-155 inhibitor group. (C) Western blot presenting the level of autophagy related proteins expressed in each transfection group $\left({ }^{* *} \mathrm{P}<0.01, \mathrm{n}=3\right)$. (D) The RT-qPCR data demonstrated that LC3 I/II was overexpressed while P62 had a low expression level in the miR-155 inhibitor group $\left({ }^{* *} \mathrm{P}<0.01, \mathrm{n}=3\right)$. CCK-8, cell counting kit-8; OD, optical density; SOD, Superoxide Dismutase; HUVEC, Human umbilical vein endothelial cell; LC3, Microtubule Associated Protein 1 Light Chain $3 \alpha$; P62, Nucleoporin 62; 3-MA, 3-methyladenine; miR-155 NC mi, miR-155 mimic negative control; miR-155 NC in, miR-155 inhibitor, negative control. 
A
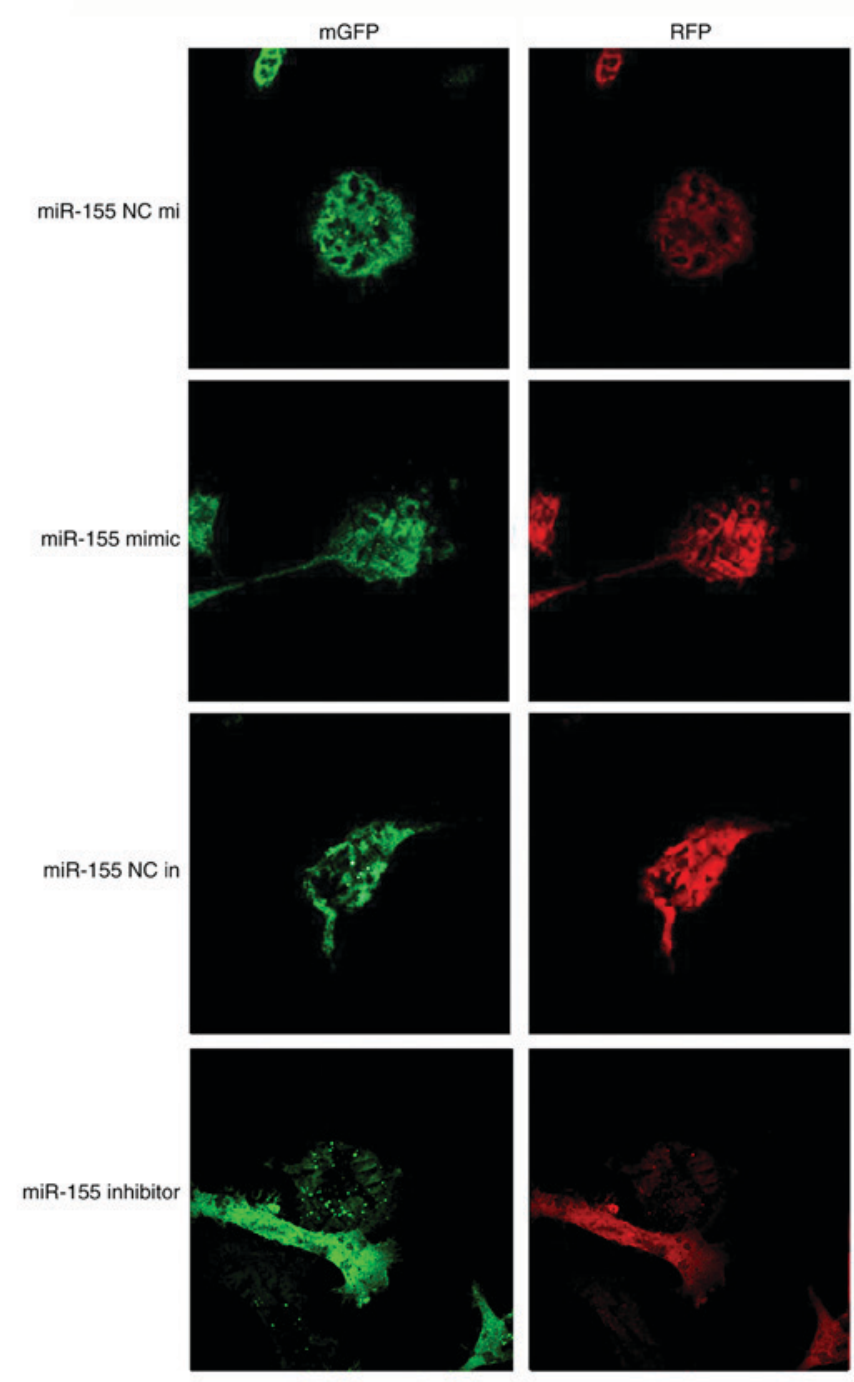

B

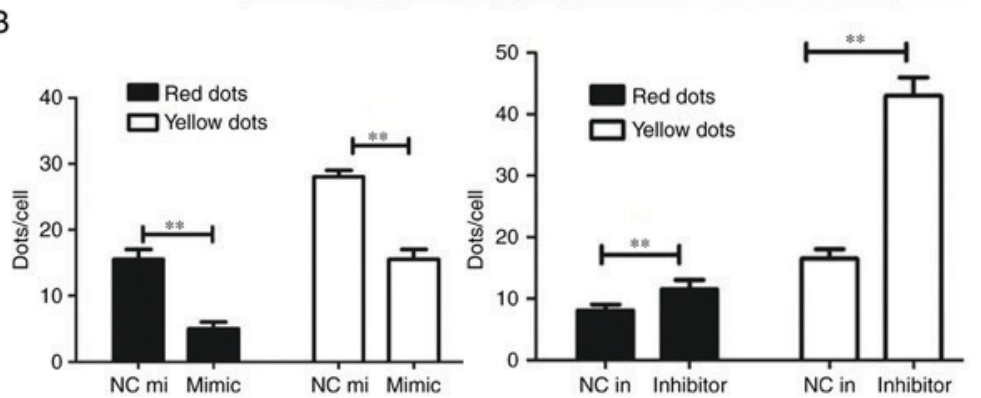

Figure 3. miR-155 promotes the proliferation of endothelial cells and decreases intracellular reactive oxygen species damage via modulating autophagy. (A) Representative image (magnification, x100) and (B) statistical data from the groups transfected with the RFP-mGFP-LC3-adenovirus and miR-155. The number of yellow dots per cell in the miR-155 inhibitor group were increased. ${ }^{* *} \mathrm{P}<0.01(\mathrm{n}=3)$. GFP, green fluorescent protein; RFP, red fluorescent protein; NC in, miR-155 inhibitor negative control; mimic, miR-155 mimic; NC mi, miR-155 negative control mimic; Inhibitor, miR-155 inhibitor.

the miR-155 inhibitor negative control group (Fig. 2A). The SOD assay data confirmed that the suppression of miR-155 can protect HUVECs from oxidative stress (Fig. 2B). Western blotting was used to determine whether autophagy was involved in miR-155-mediated HUVEC proliferation and increase the activation of ROS. The result demonstrated that LC3 was overexpressed and the P62 had low protein expression levels in the miR-155 inhibitor group (Fig. 2C). The results of RT-qPCR corroborated these findings (Fig. 2D). The expression of LC3 and number of yellow dots were increased when miR-155 was downregulated (Fig. 3A and B). The results indicate that suppression of miR-155 promotes the proliferation of endothelial cells and decreases intracellular ROS damage via modulating autophagy.

miR-155 regulates autophagy via modulation of ATG5 in HUVECs. To explore the mechanism of how miR-155 regulates autophagy in HUVECs, the expression of ATG5 was detected. The results demonstrated that the expression of ATG5 was decreased when miR-155 was overexpressed (Fig. 4A). Furthermore, when 3-MA was used to inhibit autophagy, ATG5 protein and mRNA expressions were also 

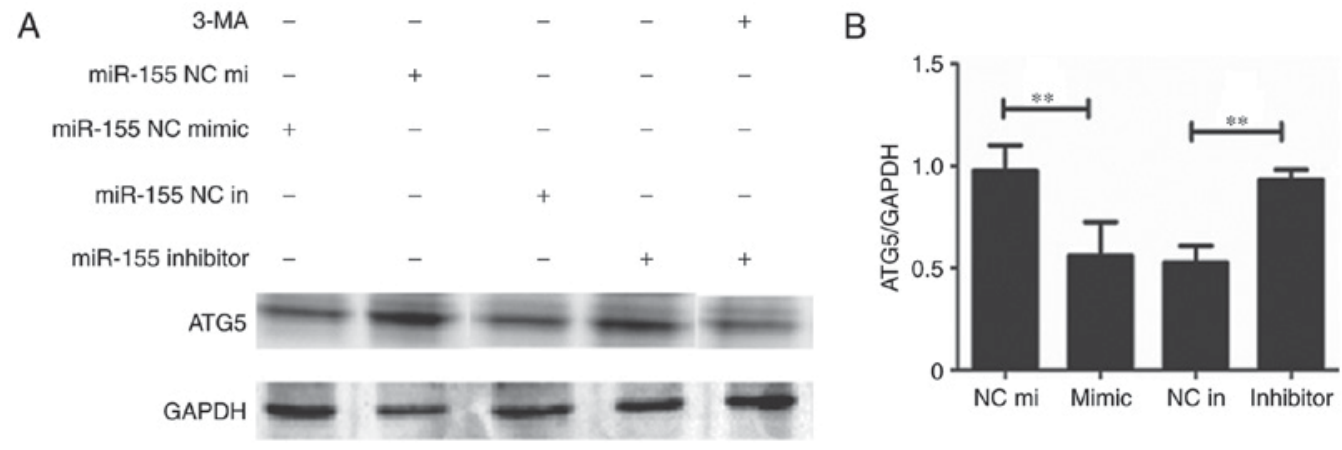

Figure 4. The representative image of (A) western blot analysis and (B) quantitative analysis of the RT-qPCR, demonstrating that the expression of ATG5 was decreased in the miR-155 mimic group. The level of ATG5 was also decreased in the group of 3-MA and miR-155. ${ }^{* *} \mathrm{P}<0.01$ (n=3). 3-MA, 3-methyladenine; RT-qPCR, reverse transcription-quantitative polymerase chain reaction; ATG5, Autophagy Related 5; NC in, miR-155 inhibitor negative control; mimic, miR-155 mimic; NC mi, miR-155 negative control mimic; Inhibitor, miR-155 inhibitor.

decreased (Figs. 4). These results indicate that miR-155 regulates autophagy in HUVECs via decreasing the expression of ATG5.

\section{Discussion}

Oxidative stress can cause endothelial cells to produce ROS, which can lead to protein dysfunction and DNA fragmentation, as well as morphological changes in endothelial cells (3). In the present study, oxidative stress cell models were established using different concentrations of $\mathrm{H}_{2} \mathrm{O}_{2}$. The expression of LC3 and P62 were detected to explore the suitable concentration, which can either induce autophagy or protect against death from apoptosis, culminating in the selection of $400 \mathrm{nmol} / 1$ $\mathrm{H}_{2} \mathrm{O}_{2}$ to establish cell models for oxidative stress.

Several studies have demonstrated that miR-155 serves an essential role in various physiological and pathological processes, for example, miR-155 is an inhibitor of autophagy in chondrocytes and contributes to the pathogenesis of OA (9), and miR-155 is downregulated in familial adenomatous polyposis and modulates WNT signaling by targeting AXIN1 and transcription factor 4 (18). Previous reports have demonstrated that miR-155 can inhibit activated caspase-3, and induce apoptosis in cancer $(16,19)$. Previous research has demonstrated that there were complex interactions between autophagy and apoptosis. These studies suggest that miR-155 may also modulate autophagy in heart disease (20-22).

Autophagy is a highly conserved process that maintains cellular homeostasis (21). Under conditions of oxidative stress, autophagy can degrade proteins to provide essential amino acids and energy (23). A previous report demonstrated that unregulated autophagy can aid in endothelial cell survival from intracellular peroxidation damage (24).

In the present study, the effects of miR-155 on endothelial cells under conditions of oxidative stress were investigated. Firstly, attenuated miR-155 expression can reduce ROS overproduction in $\mathrm{H}_{2} \mathrm{O}_{2}$-treated HUVECs, which means modulating miR-155 can prevent HUVECs from intracellular peroxidative damage. In addition, the activation of ROS was decreased and cell proliferation was increased when the expression of miR-155 was inhibited. The results indicated that inhibition of miR-155 may increase the level of autophagy and promote the proliferation of HUVECs. Summarily, the data demonstrated that inhibiting miRNA-155 prevents endothelial cells from oxidative damage via regulating the level of autophagy.

A previous study reported that, the overexpression of ATG5 significantly promoted angiogenesis in endothelial progenitor cells (12). ATG5 can combine with the proteins autophagy related 12 and autophagy related 16 to generate a macromolecular complex that promotes the formation of an autophagosome (23). It has been reported that endothelial cells will lose the ability of tubule formation and migration following ATG5 knockdown (11). Emphasizing that ATG5 can modulate autophagy and the function of endothelial cells. In the present study, the mechanism of miR-155 in modulating autophagy was investigated via detecting the expression of ATG5. The results demonstrated that inhibited miR-155 increases the expression of ATG5, which indicated that miR-155 modulates autophagy through decreasing the expression of ATG5.

The repair of endothelial cell dysfunction is the foundation for atherosclerosis treatment at the molecular level.

The present study attempted to verify that inhibiting the expression of miR-155 may protect endothelial cells from intracellular peroxidative damage and promote cell proliferation via modulating autophagy. This provides a novel insight into miRNAs as potential therapeutics for the treatment of heart disease.

\section{Acknowledgements}

Not applicable.

\section{Funding}

The present study was supported by grants from the National Natural Science Foundation of China (grant no. 81270224).

\section{Availability of data and materials}

The datasets used and/or analyzed during the current study are available from the corresponding author on reasonable request.

\section{Authors' contributions}

HFC and HW conceived and designed the study, completed the majority of the experiments and wrote the manuscript. MYLG, 
LZ, FLH, YKS and XHP provided advice and materials, and participated in the majority of experiments, data analysis and writing of the manuscript.

\section{Ethics approval and consent to participate}

Not applicable.

\section{Patient consent for publication}

Not applicable.

\section{Competing interests}

The authors declare that they have no competing interests.

\section{References}

1. Liu J, Bi X, Chen T, Zhang Q, Wang SX, Chiu JJ, Liu GS Zhang Y, Bu P and Jiang F: Shear stress regulates endothelial cell autophagy via redox regulation and Sirt1 expression. Cell Death Dis 6: e1827, 2015.

2. Wang R, Yang Q, Wang X, Wang W, Li J, Zhu J, Liu X, Liu J and $\mathrm{Du} \mathrm{J}$ : FoxO3 $\alpha$-mediated autophagy contributes to apoptosis in cardiac microvascular endothelial cells under hypoxia. Microvasc Res 104: 23-31, 2016.

3. Zhang L, Wei J, Ren L, Zhang J, Wang J, Jing L, Yang M, Yu Y, Sun $Z$ and Zhou X: Endosulfan induces autophagy and endothelial dysfunction via the AMPK/mTOR signaling pathway triggered by oxidative stress. Environ Pollut 220: 843-852, 2017.

4. He X, Zhao M, Bi XY, Yu XJ and Zang WJ: Delayed preconditioning prevents ischemia/reperfusion-induced endothelial injury in rats: Role of ROS and eNOS. Lab Invest 93: 168-180, 2013.

5. Zhao H, Han Z, Ji X and Luo Y: Epigenetic regulation of oxidative stress in ischemic stroke. Aging Dis 7: 295-306, 2016.

6. Donners MM, Wolfs IM, Stöger LJ, van der Vorst EP, Pöttgens CC, Heymans S, Schroen B, Gijbels MJ and de Winther MP Hematopoietic miR155 deficiency enhances atherosclerosis and decreases plaque stability in hyperlipidemic mice. PLoS One 7: e35877, 2012.

7. Ma X, Ma C and Zheng X: MicroRNA-155 in the pathogenesis of atherosclerosis: A conflicting role? Heart Lung Circ 22: 811-818, 2013.

8. Hulsmans M, De Keyzer D and Holvoet P: MicroRNAs regulating oxidative stress and inflammation in relation to obesity and atherosclerosis. FASEB J 25: 2515-2527, 2011.

9. D'Adamo S, Alvarez-Garcia O, Muramatsu Y, Flamigni F and Lotz MK: MicroRNA-155 suppresses autophagy in chondrocytes by modulating expression of autophagy proteins. Osteoarthritis Cartilage 24: 1082-1091, 2016.

10. Zhang L, Yu Y, Xia X, Ma Y, Chen XW, Ni ZH and Wang H: Transcription factor E2-2 inhibits the proliferation of endothelial progenitor cells by suppressing autophagy. Int J Mol Med 37: $1254-1262,2016$

11. Du J, Teng RJ, Guan T, Eis A, Kaul S, Konduri GG and Shi Y: Role of autophagy in angiogenesis in aortic endothelial cells. Am J Physiol Cell Physiol 302: C383-C391, 2012.
12. Hu N, Kong LS, Chen H, Li WD, Qian AM, Wang XY, Du XL, Li CL, Yu XB and Li XQ: Autophagy protein 5 enhances the function of rat EPCs and promotes EPCs homing and thrombus recanalization via activating AKT. Thromb Res 136: 642-651, 2015.

13. Zhang J, Deng H,Liu L, Liu X, Zuo X, Xu Q, Wu Z,Peng X and Ji A: $\alpha$-lipoic acid protects against hypoxia/reoxygenation-induced injury in human umbilical vein endothelial cells through suppression of apoptosis and autophagy. Mol Med Rep 12: 180-186, 2015.

14. Livak KJ and Schmittgen TD: Analysis of relative gene expression data using real-time quantitative PCR and the 2(-Delta Delta C(T)) method. Methods 25: 402-408, 2001.

15. Zeng M, Wei X, Wu Z, Li W, Li B, Fei Y, He Y, Chen J, Wang P and Liu X: Reactive oxygen species contribute to simulated ischemia/reperfusion-induced autophagic cell death in human umbilical vein endothelial cells. Med Sci Monit 20: 1017-1023, 2014.

16. Weber M, Kim S, Patterson N, Rooney K and Searles CD: MiRNA-155 targets myosin light chain kinase and modulates actin cytoskeleton organization in endothelial cells. Am J Physiol Heart Circ Physiol 306: H1192-H1203, 2014.

17. Chen G, Zhang W, Li YP, Ren JG, Xu N, Liu H, Wang FQ, Sun ZJ, Jia J and Zhao YF: Hypoxia-induced autophagy in endothelial cells: A double-edged sword in the progression of infantile haemangioma? Cardiovasc Res 98: 437-448, 2013.

18. Prossomariti A, Piazzi G, D'Angelo L, Miccoli S, Turchetti D, Alquati C, Montagna C, Bazzoli F and Ricciardiello L: miR-155 is downregulated in familial adenomatous polyposis and modulates WNT signaling by targeting AXIN1 and TCF4. Mol Cancer Res: Aug 2, 2018 (Epub ahead of print).

19. De Santis R, Liepelt A, Mossanen JC, Dueck A, Simons N, Mohs A, Trautwein C, Meister G, Marx G, Ostareck-Lederer A and Ostareck DH: MiR-155 targets Caspase-3 mRNA in activated macrophages. RNA Biol 13: 43-58, 2016.

20. Jia QW, Chen ZH, Ding XQ, Liu JY, Ge PC, An FH, Li LH, Wang LS, Ma WZ, Yang ZJ and Jia EZ: Predictive effects of circulating miR-221, miR-130a and miR-155 for coronary heart disease: A multi-ethnic study in China. Cell Physiol Biochem 42: 808-823, 2017.

21. Galluzzi L, Pietrocola F, Levine B and Kroemer G: Metabolic control of autophagy. Cell 159: 1263-1276, 2014.

22. Tang Y, Li J, Li F, Hu CA, Liao P, Tan K, Tan B, Xiong X, Liu G, $\mathrm{Li} \mathrm{T}$ and Yin Y: Autophagy protects intestinal epithelial cells against deoxynivalenol toxicity by alleviating oxidative stress via IKK signaling pathway. Free Radic Biol Med 89: 944-951, 2015.

23. Wang W, Li C, Li W, Kong L, Qian A, Hu N, Meng Q and Li X: MiR-150 enhances the motility of EPCs in vitro and promotes EPCs homing and thrombus resolving in vivo. Thromb Res 133: 590-598, 2014.

24. Higdon AN, Benavides GA, Chacko BK, Ouyang X, Johnson MS, Landar A, Zhang J and Darley-Usmar VM: Hemin causes mitochondrial dysfunction in endothelial cells through promoting lipid peroxidation: The protective role of autophagy. Am J Physiol Heart Circ Physiol 302: H1394-H1409, 2012.

This work is licensed under a Creative Commons Attribution-NonCommercial-NoDerivatives 4.0 International (CC BY-NC-ND 4.0) License. 